\title{
Alcohol-Related Carcinoma
}

National Cancer Institute

\section{Source}

National Cancer Institute. Alcohol-Related Carcinoma. NCI Thesaurus. Code C27927.

A carcinoma that is caused by alcohol abuse. 